\title{
Extra-linguistic Constraints \& Parameters in the Translation Process: A Descriptive Study
}

\author{
Ali Almanna ${ }^{1, *}$ \\ ${ }^{1}$ English and Translation Studies at JIC, English Language Centre, Saudi Arabia \\ *Correspondence: English and Translation Studies at JIC, English Language Centre, Saudi Arabia \\ E-mail: a_abid12@yahoo.co.uk
}

Received: July 9, 2013

Accepted: July 17, $2013 \quad$ Online Published: August 30, 2013

doi:10.5430/wjel.v3n3p27

URL: http://dx.doi.org/10.5430/wjel.v3n3p27

\begin{abstract}
The translation process at its macro level is seen here as an activity regulated by a number of factors. Translators are not working randomly in their own rights, but rather they work for, and are affiliated to, specific companies, publishing houses, organizations, and the like. These bodies have developed over time certain criteria and descriptions for selecting, representing and consuming the translated materials. As such, when deciding their global strategy, translators and all parties involved in the translation process at its macro level encounter a plethora of constraints and parameters. Some of these constraints and parameters are driven by the text per se while others come from outside, i.e. non-verbal constraints, such as the relationship between the interfacing cultures, the master discourse of translation, the power of patronage, the type of audience, the purpose of translation, generic conventions and discourse constraints.

The central focus of this study is to explore the main parameters and constraints faced by translators and all those involved in the translation process. The final shape of the target text is seen here as a result of a process in which translators, and other parties, do their best to accommodate the constraints imposed on them and to adopt what they deem to be an appropriate strategy or strategies. It has been shown that the final shape of the translation is determined not only by the text-driven constraints and parameters imposed on the part of the translator, but by both verbal constraints (i.e. text-driven constraints) and non-verbal constraints, i.e. extra-linguistic constraints. The relationship between constraints and strategies is not a one-to-one relationship, but rather the strategy is sometimes a result of more than one constraint.
\end{abstract}

Keywords: culture; (master) discourse; power of patronage; purpose of translation; genre and text typology

\section{Introduction}

The translator is a focal element in the translation process. Unlike the writer of the ST or reader of the TT, s/he has the double responsibility of being both the ST receptor and the TT sender. As such, s/he is involved in a great number of tasks, such as reading, analysing, interpreting, comprehending, transferring, restructuring, adapting, improving, evaluating and the like (Bell, 1991; Belhaaj, 1998).

In order to be in a position to determine the appropriateness of what global strategy to apply, the translator needs first to operate at the macro-level of the translation process to ascertain the text type, the genre, the intended readership and so on. Only then can the translator move to the micro-level of the process to embark on what Hall (2008: 26) describes as

the procedural phase that requires the lexical and syntactic choices and pragmatic and stylistic decisions that he/she sees will best transmit the communicative effect of the source text to the target readership, taking into account evaluation of that readership's cognitive capabilities.

As such, prior to embarking on the actual act of translating, translators are influenced by a variety of factors, such as the type of audience, purpose of translation, context of situation, power of patronage, generic conventions, their own ideology and competence and so on. In this regard, Darwish (2009: 2-3) comments:

Translation decision making is a process that is circumvented by many constraints at various levels and stages. 
These constraints, which are external, internal, physical and non-physical, must be removed in order to generate alternatives that achieve the objectives of the translation process within a defined scope, parameters and strategies.

Although Darwish's view is valid, it however ignores the positive effects such constraints might play in forming the final shape of the TT. So, the argument here is that although these constraints often restrain translators, thereby limiting their scope of freedom in dealing with texts through translation, they nonetheless offer translators opportunities to enhance their creativity in translation.

Within this context, the TT is seen here as a result of a process in which translators deploy their efforts to accommodate the constraints imposed on them and adopt what they deem to be an appropriate strategy or strategies. To put this differently, spotting the source of the difficulty that slows the translator's progress on the one hand, and choosing among the available strategies on the other, translators find themselves prioritizing among competing elements. According to Lefevere (1992: xiv), translators operate under five constraints, namely:

1. Power of patronage;

2. Poetics;

3. The universe of discourse;

4. Structural differences between the SL and TL; and

5. The translator's ideology.

Chesterman (2000: 78-9) relates these constraints proposed by Lefevere to 'norms of translation', such as 'the expectancy norm', 'accountability norm', 'relation norm' and 'communication norm' (these norms are discussed later on in this paper). Lefevere (1992: 12-18) stresses the importance of the translator's own ideology and the dominant TL poetics over the other types of constraints as they are the apparent determiners of the translated work. These two types of constraints, as Hatim and Munday (2004: 100) stress, will "manifest themselves in the way texts are consciously or unconsciously brought into line with dominant world views and/or dominant literary structures". Bassnett and Lefevere (1998) overstate that ideology influences every single aspect of translation, and that translation is the product of ideology from which it cannot free itself. But although ideology has a crucial influence on the product of translation, there are other parameters and constraints besides ideology per se that determine the final shape of any translation.

Other types of constraints include previous translations of the "same genre, author". So, "the existence of previous translations of classical works like Shakespeare's implies that any reference to his characters is usually subject to a process of linguistic translation that the same conventional proper noun would not undergo in normal conditions" (Aixlela, 1996: 67). Translating Othello into عطيل 'Utaīl in Arabic is a good example. In this respect, Al-Qinai (2005: $519)$ rightly comments:

Names of institutes, fictional, non-fictional and biblical characters that have gained a translational form will usually force the translator to adopt the established form regardless of whether it is correct or not.

Closely related to this is the influence of the mother tongue on the translation product; translation competence, the translator's idiolect and habitus, the constraints of space and time, among others. Within this context, translation constraints can be classified into four main types:

1. Extra-linguistic constraints: These include the translation purpose, intended readership, generic conventions, master discourse of translation, power of patronage, cultural (macro-level), discoursal, and text typological constraints, as well as existing (past) translations of the same text or similar texts;

2. Norm-imposed constraints: These include expectancy, accountability, relation and communication norms (see Chesterman, 2000: 87-89);

3. Translator-related constraints: These include habitus, ideology, idiolect, competence and fear; and

4. Text-driven constraints: These include language-related, textual, cultural (micro-level), communicative, pragmatic, semiotic and stylistic constraints.

For the purposes of this study, only non-verbal constraints, i.e. extra-linguistic constraints, will be discussed in terms of their effect on the final shape of the translation. 


\section{Objectives and Methodology}

In the field of Translation Studies, many attempts have been made to describe the translation process; however, most of these attempts have focused on the micro level of the process, thereby ignoring the other factors that play a crucial role in determining the final shape of the TT (see for instance Nida's sociolinguistic model (1964), Catford's formal linguistic model (1965), Levy's model based on theory of communication (1966), Steiner's (1975) hermeneutic approach, Newmark's (1988) descriptive model, Bell's model based on memory system (1990) among others).

The ultimate objective of this study is to provide the reader with a general description of the translation process at its macro-level from the perspective of translation as a project achieved by a number of people, not only the translator. In describing the translation process at its macro-level, the focus of attention is shifted towards the parameters and constraints that translators and all those involved in the translation process encounter prior to embarking on the actual act of translating. To this end, a conceptual research design was adopted, supported by a number of examples taken from various translations done by different translators on different text types between Arabic and English. It was felt that a conceptual research design was most apt for such types of studies that attempt to define, or refine a social phenomenon by using a different perspective, different research materials, and so on. In this regard, Maxwell (2005: 222-223; emphasis in origin) holds that a conceptual research design is

a formulation of what you think is going on with the phenomena you are studying-a tentative theory of what is happening and why. Theory provides a model or map of why the world is the way it is. It is a simplification of the world, but a simplification aimed at clarifying and explaining some aspects of how it works. It is not simply a 'framework', although it can provide that, but a story about some phenomenon.

In an attempt to distinguish between conceptual research and empirical research, Williams and Chesterman (2002: 58) state that conceptual research normally aims to:

a) define and clarify concepts;

b) interpret or reinterpret ideas;

c) relate concepts into larger systems; and

d) introduce new concepts or metaphors or frameworks that give a better understanding of the object of research.

Empirical research, on the other hand, aims to

a) have new data or new information derived from the observation of data or from experimental work;

b) obtain solid evidence which supports or disconfirms hypotheses; or

c) generate new hypotheses or claims.

Both approaches are necessary in the field of translation studies as in other fields. However, as the main aim of this study is to provide the reader with a comprehensive description of the translation process at its macro level, the focus of attention is shifted towards ideas and/or concepts, rather than data; hence adopting a conceptual research design, rather than an empirical one.

\section{Extra-linguistic Constraints \& Parameters}

When deciding their global strategy, translators usually ask themselves a number of questions that would identify the text type, genre, the intended readership of the TT, the translation purpose, and the function of the TT, among other things, with a view to forming a global strategy before embarking on the actual act of translating. In this regard, Hatim and Mason (1997: 11) remark: "Translators' choices are constrained by the brief for the job which they have to perform, including the purpose and status of the translation and the likely readership and so on". Parallel to these, the publisher's attitude, or the agency's policy, the presence of the ST in a bilingual edition, and the relationship between the source and target cultures (self and other) are often of equal influence in deciding the appropriateness of a particular global strategy. In this regard, Venuti (2000: 468) comments:

Translation never communicates in an untroubled fashion because the translator negotiates the linguistic and cultural differences of the foreign text by reducing them and supplying another set of differences, basically domestic, drawn from the receiving language and culture to enable the foreign to be received there.

This entails that translators do not work randomly, but are rather influenced by particular constraints that are of a macro nature (extra linguistic constraints). The translator sometimes receives some information (the translation brief) from the translation commissioner (client, agent, translation project manager or publisher), which implicitly or explicitly 
gives indications as to what global strategy to adopt. For instance, the poetics of translation into Arabic requires those in charge of translation quality control to take the necessary steps to ensure that blasphemous segments and other taboo segments be eliminated or, at least, be watered down or euphemized. Such editorial constraints do not usually present themselves when translating into English where such sensitivities are culturally tolerated.

\subsection{The Relationships between Cultures}

When translating from language/culture $A$ to language/culture $B$, translators are influenced by the way in which they look at the other and vice versa. This way of viewing the other and/or the way in which the other sees 'us' influences the translation process at every stage of translation. In this regard, Bassnett and Trivedi (1999: 2) write: "Translation is not an innocent, transparent activity but is highly charged with signification at every stage; it rarely, if ever, involves a relationship of equality between texts, authors or systems". As such, translation is a cultural act, associated with "a highly manipulative activity that involves all kinds of stages in the process of transfer across linguistic and cultural boundaries" (ibid).

Approached from such a perspective, another type of constraint derived from the struggle between the culture we are translating from and the culture we are translating to, can be identified. Faiq (2008: 27-30) emphasizes that translation presents prime sites for examining a great number of issues, such as power relations, race, gender, (post-) colonialism, publishing strategies, censorship and otherness whereby all parties involved in the translation process at its macro-level (be they publishers, editors, translation project managers, translation quality controllers and translators) are highly influenced by their own culture and the way it views the cultures they are translating from or to. The way, in which they see self and other (source and target), influences among other factors (see below) every single aspect of the translation process, starting from selecting the ST for translation up to presenting it for the target reader. As far as the relationship between the source culture and target culture is concerned, it is worth mentioning that the relationship is not always equal, but rather a target culture, as Robyns (1994: 409-420) concludes, may take one of the following positions towards the source culture:

1. Imperialist, i.e. the target culture encourages transporting foreign materials from the source culture, provided that the transported materials are naturalized in accordance with the established systems of the target culture and its norms and conventions;

2. Defensive, i.e. the target culture regards the source culture as a threat to its identity, thereby avoiding any influence the target culture might exercise;

3. Trans-discursive, i.e. the two cultures see each other equally; or

4. Defective, i.e. the target culture looks at the source culture as a capable culture that can compensate for the target cultural deficiencies.

So, whatever the relationship between the interfacing cultures, be it imperialist, defensive, trans-discursive or defective, there will be some sort of influence on the translator prior to embarking on the actual act of translating. However, the influence may well reach its peak when the relationship is imperialist whereby the target culture adopts a colonial approach in transporting the foreign materials. Such an imperialist relationship between the source and the target cultures has encouraged the translation of literary works that are in line with existing stereotypical representations conjured up in the target readers' minds towards the original culture regardless of the literary quality of the works.

\subsection{Master Discourse of Translating}

In addition to being influenced by their own culture and the way they see the other, translators, before starting the actual act of translating, may find themselves working for and affiliated to specific bodies with certain criteria and descriptions that are formulated for the translated materials. Such criteria and descriptions form established systems with specific norms and conventions for selecting, representing, producing and consuming the foreign materials, thereby producing a master discourse of translation through which identity and difference (self and other) are discussed and negotiated and within which translating is done (cf. Faiq, 2007 and 2008). Adhering to the constraints imposed by virtue of a master discourse on all parties involved in a macro-level of translation, self and other (source and target) become situated into ways of representation inherited in the shared experience and institutional norms of the self. Otherness is therefore measured according to a number of possibilities within the master discourse. In this regard, Faiq (2008: 30; emphasis his) rightly comments:

When the other is feared, the lexical strategies (language choices) one expects are those that realize hierarchy, subordination and dominance. Otherness can and often does lead to the establishment of stereotypes, which usually come accompanied by existing representations that reinforce the ideas behind them. The presentation of 
others through translation is a powerful strategy of exclusion used by a self as normal and moral (Said, 1995). Not surprising, this exclusion is also accompanied by an inclusion process of some accepted members from the other as long as the acceptees adopt and adapt to the underling master discourse and its associated representational system and ideology of the accepting self, acceptors [...].

The traditional Western discourse in general and the more recent Anglo-American discourse in particular have been hostile to Arab-Islamic culture. For instance, Barber (1995: 53-63) envisions two parallel futures for our globe: a McWorld informed by modernity, science and technology representing the West and a McTripe dominated by backwardness and tribal/sectarian violence representing the East (especially Arab-Muslim cultures). Due to such a dominant discourse, some Western publishers still adopt normative and positivist approaches, in which the world is divided into Self and Other, to translating from Arabic to English, thereby encouraging the translation of works which usually deal with blasphemy, feminist concepts, human rights, sex and so on - this is because such issues readily feed into their own culture's stereotypical images towards the other.

\subsection{Generic Conventions}

Another type of constraint imposed on the translator prior to starting the actual act of rendering is related to genre. Following Kress (1985: 19), Hatim and Mason (1990: 69-70) define genre as "conventionalized forms of text which reflect the functions and goals involved in the language activity characteristic of particular social occasions". These genres, according to Kress (1985: 9), "provide a precise index and a catalogue of the relevant social occasions of a community at a given time". These generic conventions, on the one hand, help translators expect the lexical items, the syntactic structures, the register members and the like which are normally used in such a genre, and restrict them from opting for "non-member candidate selections from entering the generic sphere", on the other (Bayar, 2007: 137). Again, translators are not working here randomly. Rather, they operate under generic constraints, which represent the conventionalized forms of the marriage contract that make the translator understand مؤجل and in the following example as مؤخر and and help select 'down-payment' and 'deferred payment' respectively in English rather than other options available as equivalents. Also, it is the generic conventions that make the translators opt for 'male spouse' and 'female spouse' rather than 'bridegroom' or 'bride' respectively:

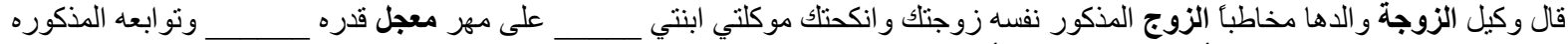

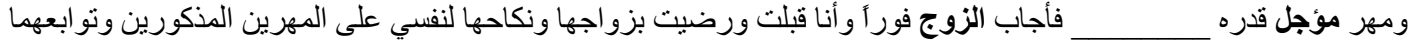

The representative for the female spouse (her father) said, addressing the aforementioned male spouse, "I have given you my daughter___ in marriage for a dowry the down-payment of which is___ the extras of which are mentioned above and the deferred payment of which is__. The male spouse immediately replied, "I accept your daughter in marriage and confirm the dowry's down-payment, deferred payment and extras stipulated above".

(Adapted from Hatim et al 1995: 86-87; emphasis added)

Here, it is the generic conventions that could possibly give rise to such unidiomatic renderings, such as 'male spouse' and 'female spouse', which are not often used in other genres. However, legislative writings still retain particular remarkable features that distinguish it from other genres, such as the length of sentences, the complex structures, the use of archaic expressions, the use of the lexical item and its synonym, the use of a particular preposition and its synonym, the dearth of punctuation marks and so on (cf. Crystal and Davy, 1969).

\subsection{Discoursal Constraints}

Closely associated to genre is the term 'discourse', which can be defined as 'institutionalized modes of speaking and writing which give expression to particular attitudes towards areas of socio-cultural activity" Hatim and Mason (1997: 144). In this respect, Hatim (1997a: 206) comments:

As the mouthpiece of institutions, discourse becomes the vehicle of attitudinal expression, and the framework within which terms of reference pertaining to a given cultural code are established. Structurally, discoursal considerations determine the way texts concatenate (often in sequence, sometimes embedded within each other).

So, when the original writer's selections from the language resources give expression to a particular attitude or point of view towards a certain socio-cultural activity, say racism, feminism, liberalism and the like, the meanings of the text at hand with the aid of the conventionalized forms of the genre will be clearly understood. Abu Libdeh (1991: 121) remarks that "the meanings of a text are derived from the meanings (or conventions) of a genre and of a discourse. Discourse determines what is to be said; genre determines how it will be said". 
Approached from a translation standpoint, these institutionalized modes of speaking or writing that give expression to attitudes towards a certain socio-cultural activity (i.e. discourse) will impose another type of constraint on translators, in particular when their attitudes towards such a social-cultural activity are different, or the attitude itself is not in line with the target cultural norms or with the specific norms and conventions of the established systems for selecting, representing, producing and consuming foreign materials, i.e. the master discourse of translation (cf. Faiq, 2007). In the following example quoted from Nawal El-Saadawi's novel الحب في زمن النفb and translated into English by Basil Hatim and Malcolm Williams as 'Love in the Kingdom of Oil', the translators being influenced by the master discourse of translation from Arabic into English or the poetics of translating from Arabic into English have altered the institutionalized modes of writing to give different expression to attitudes towards such a social-cultural activity (i.e. the relationship between men and women), thereby producing a different discourse:

هل خرجت يوما عن طاعنك؟

Has she ever previously left the conjugal home without your consent?

(cited in Abuelma'tti, 2005: 210)

Here, the translation refers to the woman as if being in prison and not allowed to go out unless she has permission from her master/husband. Such a discoursal restructuring adds a characteristic that would invoke in the mind of the target reader images of oppression and slavery practised on women in the Arab world (cf. Abuelma'tti, 2005: 210). This discoursal manipulation is enthusiastically welcomed by the Western publisher/reader as it reinforces the existing stereotypical representations conjured up in the minds of the Western readers towards the Arab/Islamic world on the one hand, and it accords well with the master discourse of translating from Arabic into English on the other. In this regard Abuelma'tti (2005: 181) comments:

Translation traffic from Arabic, thus, creates a set of characters and ideologies organized around the contrast between the West (Self) and East (Other) in which the exotic Orient is represented in a table of accessible information, and so, a typical cultural product of Western dominance (Aydin 1994). The ideology of cultural globalization today subjugates the Arab/Islamic world to translation projects and strategies that are suppressive and which eventually result in perverted images.

\subsection{Skopos of Translation}

Another critical factor that has a great influence on the global strategy is the translation purpose. The translation purpose or skopos (as it is known in the literature) is a crucial factor that determines the final shape of the translation. Drawing on the theory of Translational Action introduced by the Finland-based German, Justa Holz-Manttari, Skopos theory claims that the crucial factor that determines the final shape of the TT is the purpose of the translation. Skopos theory "relies on key concepts in pragmatics, such as intention and action" (Hatim, 2001: 74). According to Skopos theory (cf. Nord, 1997: 27-28; Hatim, 2001: 74), there are three types of purposes:

a) The general purpose, i.e. the purpose of the translator in translating the text, i.e. the translator's motivation, such as gaining reputation, earning a living and so on.

b) The communicative purpose, i.e. what is the purpose of the TT? Is it for persuading, instructing or just for information?

c) The purpose of the translation strategy, i.e. why is a certain strategy adopted while others are excluded?

The general rules of Skopos theory can be summarised as follows:

1. It is the skopos of the translation that determines the shape of the translation. Knowing the purpose behind the translation enables the translator to opt for a certain global strategy, thereby excluding other available strategies;

2. There should be 'intertextual coherence' or 'fidelity' between the TT and the ST as long as the TT is "an offer of information about an existing offer of information", i.e. the ST and TT should be intertextually coherent with each other. The TT is "judged to be intertexually coherent to the extent that there is consistency between the intentionality of the source text producer, the way this is interpreted, and the way it is reexpressed with target language" Hatim (2001: 75-6);

3. The third rule is addressing the integrity of the TT itself, i.e. the TT must be intratextually coherent.

It follows that each of the skopos rules discussed above exerts certain constraints on the translator. Firstly, adopting a global strategy will undoubtedly affect the local strategies taken by the translator, i.e. reasoned decisions, such as addition, omission, deviation, lexical choice, maintaining or ignoring some stylistic features, reflecting or changing the 
register concerning specific problems of grammar, punctuation, syntax, style, comprehension and accuracy. Secondly, as long as the relationship between the ST and the TT is considered, the fidelity rule is related, to a considerable extent, to the accuracy of the translation or 'the relation norm' (cf. Chesterman, 2000). Thirdly, the rule of the integrity of the TT brings to the fore notions such as acceptability, accessibility and naturalness (see below).

\subsection{Target-language Readership}

Another factor that plays a crucial role in determining the final shape of the translation is the translator's need to take into account the target reader's expectations. This requires translators to take a number of fundamental decisions concerning the levels of acceptability and accessibility. In this regard, Baker (1992: 219) states that the TT acceptability does not "depend on how closely it corresponds to some state in the world", but rather on how the target readers access the TT and decide on its reality "whether believable, homogenous or relevant". To this end, the translator needs to render the "exact contextual meaning of the ST [...] through the medium of a TL which is acceptable to the TL reader and easily understood by him" (Adab, 1997: 9-10). In this regard, Hall (2008: 23) writes:

To achieve effective communication, the translator needs to take account of the cognitive and cultural environment of the targeted language community and its likely expectations of the transmitted text and make his/her translation as informative and accessible as possible.

This brings to mind two notions, viz. naturalness and explicitness vs. implicitness. To begin with, the salient features of naturalness, according to As-Safi and Ash-Sharifi (1997: 60-1), are 'well-formedness', 'acceptability', 'idiomaticity', 'authenticity', 'contemporaneity', 'intelligibility', 'accessibility' and 'readability'. The retention of a certain level of naturalness sometimes requires the translator to take a wide variety of fundamental decisions in this regard, such as skewing the SL syntactic structure to conform to TL syntax; slackening and/or lightening the ST propositional contents for the TT version; coordinating between obligatory and optional information and so on. As for explicitness vs. implicitness, it is very much related to "assumptions about the universe" (Bell, 1991: 188), i.e. the amount of information that the text producer, in our case the translator, assumes that s/he shares with the text receiver, i.e. the TT reader. As such, when the translators assume that the amount of information is shared between them and their intended readers, they do not need to make every piece of information explicit in the surface structure (ibid). Actually, the translator's decisions on what is relevant to the target reader are "based on his intuitions or beliefs" (Gutt, 1991: 112). Gutt holds: "The translator does not have direct access to the cognitive environment of his audience, he does not actually know what it is like - all he can have is some assumptions or beliefs about it" (ibid).

Building on such assumptions or beliefs they have about their target readers, translators opt for certain local strategies in order to live up to the target readers' expectations and realize global strategies. For instance, the English translation of Fu'ad al-Takarli's خزين اللامرئيات 'A hidden Treasure' exhibits fundamental changes whereby elements of ambiguity and culture-specific elements in the original have been omitted and/or modified to cater for the target readers' expectations:

$$
\text { ثم جاءها النصيب أخير أ فتزوجت منذ خمس سنو ات واستقرت بها الحياة هنا. }
$$

Finally, she got married five years ago. Now she's settled here.

(Husni and Newman, 2008: 234-235)

In the above example, there is a semantic repetition جاءها النصيب 'lit. the fate came to her' and تزوجت 'she got married'. Pragmatically speaking, the maxims of quality and quantity are flouted as opting for one of them is sufficient to convey the author's intention. What is of greater importance for our discussion is the first segment, i.e. 'the fate came to her' in which the locutionary act (statement that the fate came to her) is different from its illocutionary force (she got married). The translators, being aware of such a pragmatic issue, have resorted to deleting جاءها النصيب 'lit. the fate came to her' as rendering it literally would be unidiomatic and, indeed, nonsensical in English. However, from a stylistic perspective, had the translators taken into account such a semantic repetition, they could have produced a rendering, such as: 'her luck changed and she got married' or 'her turn came and she got married'.

\subsection{Text-typological Constraints}

Texts have traditionally been divided into different groups on the basis of their subject matter. It is believed, according to this method of organizing texts, that some texts share certain characteristics, such as the frequency of occurrence of particular lexical items or syntactic structures. These linguistic characteristics enable them to be organized into different types, such as poetic, legislative, technical, scientific and so on. In this respect, Bell (1991:202) writes:

Individual texts resemble other texts and it is this resemblance which is drawn upon by the text-processor in "making sense" of the text. This knowledge is, clearly, of crucial importance to the language user and any 
attempt to explain how texts are created and used must include an answer to the question "How is it, given that each text is unique, that some texts are treated as the same?"

Although this method of organizing texts according to their subject matter has been used for a long time in programmes of translation teaching, there is a substantial difficulty in working with such a text typology, in particular that related to defining the text type itself, for instance what is meant by a literary text? There is undoubtedly "a substantial degree of overlap which suggests that content, per se, is inadequate as discriminator" Bell (1991: 203). He adds that "such an approach will work with some highly ritualized genre (some types of poetry, for example) but not in the case of the majority of texts where again, and now at the formal level, there is overlap" (ibid).

In the early 1970s, the German scholar, Katharina Reiss, drawing upon the functional relationship between the ST and the TT, gave attention to the importance of linking translation method to text type. In her book co-authored with Vermeer (1984), they divided texts into three types: informative, expressive and operative, relying on a classification of language functions, presented by the German psychologist, Karl Bühler, who classified language functions into three types, namely expressive, informative and vocative. Having distinguished these three text types one from the other, Reiss added that in translating an informative text, since the main aim is to convey information to the reader, priority is given to the content rather than the form, whereas in translating an expressive text where the main aim is to impress the reader, particular attention should be paid to the aesthetic effects. However, in translating an operative text where the main aim is to persuade the reader, the focus of attention should be shifted towards extra-linguistic effect at the expense of aesthetic values and semantic content.

Working on the textuality model proposed by Beaugrande and Dressler (1981), Hatim and Mason $(1990,1997)$ designed a model of text types in translation that endorses the notion that despite the fact that texts are essentially hybrid, one particular function tends to predominate over the other functions. In their model, Hatim and Mason (ibid) classify texts into three main types, viz. exposition, argumentation and instruction:

a) Instructional texts focusing on influencing future behaviour on the part of the text receiver;

b) Expository texts where the text producers are engaged in presenting concepts, states, events, entities and relations in a non-evaluative manner; and

c) Argumentative texts focusing on the evaluation of the relations between concepts.

Regardless of the method adopted in typifying texts, what is of greater importance in this regard is that there is some sort of correlation between text type and the global strategy to be applied by the translator (cf. Hatim 1997b; Reiss 2000; Haddad 2004; Bayar 2007; Hall 2008 among others) as different text types put different demands on the translator. In this regard, Hatim (1997b: 11) states:

Being aware of the extent to which a particular text is evaluative determines the translation strategy to be adopted. [...], literal translation works admirably well with legal language لغة النص القانوني, slightly less well with exposition السرد and not always well with the more involved types of argumentation الجدل which necessitates a free translation.

In a similar vein, Bayar (2007: 144) rightly comments:

These macro-structural dimensions govern the selection of text realisation devices to create the ST just as much as they should do (i.e. as much as the translator is aware they do, and is willing to let them exert the same impact) during the TT production.

This accords well with the hybrid nature of texts. Any text type can sometimes utilize the formats of the other texts. Yet, its type is not determined according to the formats borrowed from the other text type, but is rather determined by "the text's over-all function and super-ordinate goal" Bayar (2007: 143-144).

\section{Conclusion}

Considering the translator as a social human being in the sense that $\mathrm{s}$ he lives in a certain community with certain beliefs, feelings, cultural background, ideologies, attitudes, mentality, idiosyncrasies, experiences and skills (cf. Ghazala, 2002: 161; Ghazala, 2011: 137), the translation process is envisaged in this paper as a set of constraint-motivated strategies. Within this context and as the preceding discussion has shown, the final shape of the translation is determined by the constraints imposed on the translator and all those involved in the process of translation at its macro level. Such constraints and parameters have been divided into two main types: verbal constraints, i.e. text-driven constraints, and non-verbal constraints, such as the translation purpose, generic 
conventions, intended readership, power of patronage, master discourse of translation, text typological constraints and discoursal constraints. The final shape of the translation is not determined only by the text-driven constraints, but rather by both verbal and non-verbal constraints. The relationship between constraints and strategies is not a one-to-one relationship; rather, the strategy is often a result of more than one constraint.

As Ghazala (2002: 154) argues, "unbias from the translator's point of view is a fallacy, a mirage. It exists in theory in his heart, not in mind, but in the critic's mind, not heart". He goes on to stress that "unbias in translation is mostly far-fetched in perfection, as it is sometimes not advisable or not required at all" (ibid). Such an unbias results from translators' own beliefs, backgrounds, assumptions and their set of skills and competences that motivate them to adopt certain strategies to superimpose a "certain directionality on the text in order to approximate it to, or even have it meet, [their] own or some other agent's goal" (Farghal, 2008: 1) - that is, it has nothing to do with the norms. All types of constraints not only text-driven constraints are in action together to motivate translators to select what they deem as the most appropriate local strategy for a particular translation task. It has been shown that text-driven constraints and parameters cannot effectively account for all cases of deviant translation practices. Text-driven constraints and parameters are among other factors that influence a translator's choices as there exist a number of other factors that motivate translators to opt for one strategy, or a combination of many strategies, and exclude others. Since people are different in perceiving world reality, in their tolerance to the pressure exerted on them, and in their reaction to such pressure, such a selection among available strategies is subjective rather than objective, being attributable to translators' backgrounds, attitude, ideology, idiolect and competence.

\section{References}

Abuelma'atti, Z. (2005). Translation \& Cultural Representation: Globalizing Texts, Localizing Cultures, unpublished Ph.D. UK: Salford University.

Abu Libdeh, A. J. (1991). A Discourse Perspective on Figurative Expression in Literary Works with Reference to English/Arabic Translation, unpublished Ph.D thesis: Heriot-Watt University.

Adab, B. J. (1997). Annotated Texts for Translation: French-English. Clevedon/Philadelphia/Adelaide: Multilingual Matters.

Aixlela, J. F. (1996). Culture-specific Items in Translation. In, R. Alvarez and C. A. Vidal (eds.) Translation, Power, Subversion, Clevedon/Philadelphia: Multilingual Matters, pp. 52-79.

Al-Qinai, J. (2005). Manipulation and Censorship in Translated Texts. In R. Garcia, and M. Luisa, (eds.) II AIETI. Madrid: AIETI, pp. 488-525.

As-Safi, A., \& Ash-Sharifi, I (1997). Naturalness in Literary Translation. Babel, 43(1), 60-75. http://dx.doi.org/10.1075/babel.43.1.05ass

Baker, M. (1992). In Other Words: A Coursebook on Translation. London/New York: Routledge. http://dx.doi.org/10.4324/9780203327579

Barber, B. (1992). Jihad vs. McWorld. The Atlantic Monthly, pp. 53-63.

Bassnett, S., \& Lefevere, A. (1998). Constructing Cultures: Essays on Literary Translation. Clevedon: Multilingual Matters.

\& Trivedi, H. (eds.) (1999). Post-Colonial Translation: Theory and Practice. London/New York: Printer.

Bayar, M. (2007). To Mean or Not to Mean. Damascus: Kadmous Cultural Foundation.

Beaugrande, R. de \& Dressler, W. (1981). Introduction to Text Linguistics. London: Longman.

Belhaaj, A. E. (1998). The Process of Translation: Factors, Tasks and Challenges. Saudi Arabia: Umm Al-Qura University Press.

Bell. R. (1991). Translation and Translating: Theory and Practice. London/New York: Longman.

Chesterman, A. (2000). Memes of Translation: the spread of ideas in translation theory. Amsterdam/Philadelphia: John Benjamins Publishing CO.

Darwish, A. (2009). Towards a Theory of Constraints. Retrieved on January 4, 2013 from http://www.surf.net.au/writescope/translation/constraints.html

Faiq, S. (2007). Trans-Lated: Translation and cultural Manipulation. New York: Roman and Littlefield Publishing 
Group.

(2008). The Master Discourse of Translation from Arabic. Sayyab Translation Journal, 1, 27-36.

Farghal, M. (2008). Extrinsic Managing: An Epitaph to Translational Ideological Move. Sayyab Translation Journal, 1, $1-26$.

\& Shunnaq, A. (2011). Translation with Reference to English and Arabic: a Practical Guide (2 ${ }^{\text {nd }}$ edition), Jordan: Dar Al-Hilal for Translation.

Gardiner, M. (1992). The Dialogics of Critique: M M Bakhtin and the Theory of Ideology. London: Routledge.

Ghazala, H. (2002). The Translator's Dilemma with Bias. Babel, 48(2), 147-162. http://dx.doi.org/10.1075/babel.48.2.05gha

(2006). Translation as Problems and Solution ( $7^{\text {th }}$ edition). Dar Wa Maktabat al-Hilal: Beirut.

(2011). Cognitive Stylistics and the Translator. London: Sayyab Books Ltd.

Gutt, E-A. (1991). Translation and Relevance: Cognition and Context. Oxford: Blackwell.

Haddad, S. (2004). Text Typology and the Translator: Legal Instruction under Scrutiny. Syria: Dar Tlass for Studies, Translation and Publication.

Hall. M. F. (2008). Discourse Analysis of Fictional Dialogue in Arabic to English Translation, unpublished Ph.D thesis. England: University of London.

Hatim, B. (1997a). Communication across Cultures: Translation Theory and Contrastive Text Linguistics. England: University of Exeter Press.

(1997b). English-Arabic/Arabic-English Translation: A Practical Guide. London: Saqi Books.

(2001). Teaching and Researching Translation. Edinburgh: Person Education Limited.

Shunnaq, A., \& Buckley, R. (1995). The Legal Translator at Work: A Practical Guide. Irbid: Dār Al-Hilāl for Translation and Publishing.

\& Munday, J. (2004). Translation: An Advanced Resource Book. London/New York: Routledge.

\& Mason, I. (1990). Discourse and the Translator. London: Longman.

(1997). The Translator as Communicator. London/New York: Routledge.

Husni, R., \& Newman, D. (2008). Modern Arabic Short Stories. London: Saqi Books.

Kress, G. (1985). Linguistic Processes in Sociocultural Practice. Victoria: Deakin University Press.

Lefevere, A. (1992). Translation, History, Culture: a Sourcebook. London/New York: Routledge.

(1998). Translation Practice(s) and the Circulation of Cultural Capital: Some Aeneids in English. In S. Bassnette and A. Lefevere (eds.) Constructing Cultures. Clevendon: Multilingual Matters, pp. 40-56.

Maxwell, J. A. (2005). Qualitative Research Design: an Interactive Approach (2 ${ }^{\text {nd }}$ edition). Thousand Oaks: SAGE Publications, Inc.

Mazid, B. M. (2007). Politics of Translation: Power and Ideology, Culture and X-phemism in Translation between Arabic and English. Germany: Lincom Europa.

Nord, C. (1997). Translating as a Purposeful Activity: Functionalist Approaches Explained. Manchester: St Jerome Publishing.

Reiss, K. (2000). Translation Criticism - The Potentials and Limitations. Manchester/New York: St. Jerome Publishing and American Bible Society. Translated into English by Erroll F. Rhodes.

Robyns, C. (1994). Translation and Discursive Identity. Poetics Today, 15(3), 405-428. http://dx.doi.org/10.2307/1773316

Venuti, L. (eds.) (2000). The Translation Studies Reader. London/New York: Routledge. http://dx.doi.org/10.4324/9780203446621

Williams, J., \& Chesterman, A. (2002). The Map. Manchester: St. Jerome Publishing. 